\title{
SOOT SURFACE GROWTH AND OXIDATION IN DIFFUSION FLAMES AT SUBATMOSPHERIC AND ATMOSPHERIC PRESSURES
}

\author{
C. H. Kim*,A. M. Leathy ${ }^{\dagger}$ and G. M. Faeth' \\ The University of Michigan, Ann Arbor, Michigan 48 109-2140
}

\begin{abstract}
The flame structure and the soot structure and surface reaction properties of round laminar jet diffusion flames were studied experimentally. Measurements were made along the axes of laminar jet diffusion flames fueled with acetylene-nitrogen mixtures and burning in coflowing air at pressures of $0.125,0.250,0.500$ and 1.000 atm and normal temperature. The Measurements included soot structure, soot concentrations, soot temperatures, major gas species concentrations, some radical species $(\mathrm{H}$, $\mathrm{OH}$, and $\mathrm{O}$ ) concentrations, and gas velocities. These measurements yielded local flame properties that are thought to affect soot surface reaction properties, as well as local soot surface growth and oxidation rates (the last, however, limited to measurements at atmospheric pressure for the present). Present and earlier measurements showed that soot surface growth rates could be explained by HydrogenAbstraction/Carbon-Addition (HACA) soot surface growth mechanisms in the literature with empirical steric factors in these mechanisms
\end{abstract}

* Graduate Student Research Assistant, Department of Aerospace Engineering

${ }^{\dagger}$ Research Fellow, Department of Aerospace

Engineering

A. B. Modine Professor, Department of Aerospace Engineering; Fellow, AIAA, Corresponding Author, Tel.:+1-734-764-7202,Fax: +1-734-936-0106,E-mail address: gmfaeth @umich.edu

Copyright $\odot$ by G. M. Faeth. Published by the American Institute of Aeronautics and Astronautics, Inc., with permission. having values on the order of unity, as anticipated. Similarly, soot surface oxidation rates for present fuel-rich and near stoichiometric conditions could be explained by reaction with $\mathrm{OH}$, having a collision efficiency near 0.1 , as proposed by Neoh et al. (1980) based on studies of soot surface oxidation in premixed flames, supplemented to only a minor degree by soot surface oxidation by $\mathrm{O}_{2}$.

\section{NOMENCLATURE}

$\mathrm{C}_{\mathrm{i}}=$ mass of carbon oxidized per mole of species i reacted $(\mathrm{kg} / \mathrm{kgmol})$

$\mathrm{d}=$ fuel port exit diameter (m)

$\mathrm{d}_{\mathrm{p}}=$ mean primary soot particle diameter $(\mathrm{m})$

$\mathrm{f}_{\mathrm{S}}=$ soot volume fraction (-)

Fr $=$ burner exit Froude number $(-), \mathrm{u}_{\mathrm{o}}{ }^{2} /(\mathrm{gd})$

$\mathrm{g}=$ acceleration of gravity $\left(\mathrm{ms}^{-2}\right)$

[i] =molar concentration of species i $(\mathrm{kgmol}$ $\mathrm{m}^{-3}$ )

k = Boltzmann constant $\left(\mathrm{J} \mathrm{K}^{-1}\right)$

$\mathrm{m}_{\mathrm{i}}=$ mass of molecule of species $\mathrm{i}(\mathrm{kg}$ molecule-')

$n_{p}=$ number of primary particles per unit volume $\left(\mathrm{m}^{-3}\right)$

Re = burner exit Reynolds number $(-), \mathrm{u}_{0} \mathrm{~d} / \mathrm{v}_{\mathrm{o}}$

$\mathbf{R}_{\mathbf{i}}=$ terms in the HACA soot surface growth rate formulas $\left(\mathrm{kg} \mathrm{m}^{-2} \mathrm{~s}^{-1}\right)$

$\mathrm{R}_{\mathrm{u}}=$ universal gas constant $\left(\mathrm{J} \mathrm{kgmol}^{-1} \mathrm{~K}^{-1}\right)$

$S=$ soot surface area per unit volume $\left(\mathrm{m}^{-1}\right)$

$\mathrm{t} \quad=$ time $(\mathrm{s})$

$\mathrm{T}=$ temperature $(\mathrm{K})$

$\mathrm{u}=$ streamwise velocity $\left(\mathrm{m} \mathrm{s}^{-1}\right)$

$\bar{v}_{\mathbf{i}}=$ mean molecular velocity of species $\mathrm{i}\left(\mathrm{m} \mathrm{s}^{-1}\right)$

American Institute of Aeronautics and Astronautics 


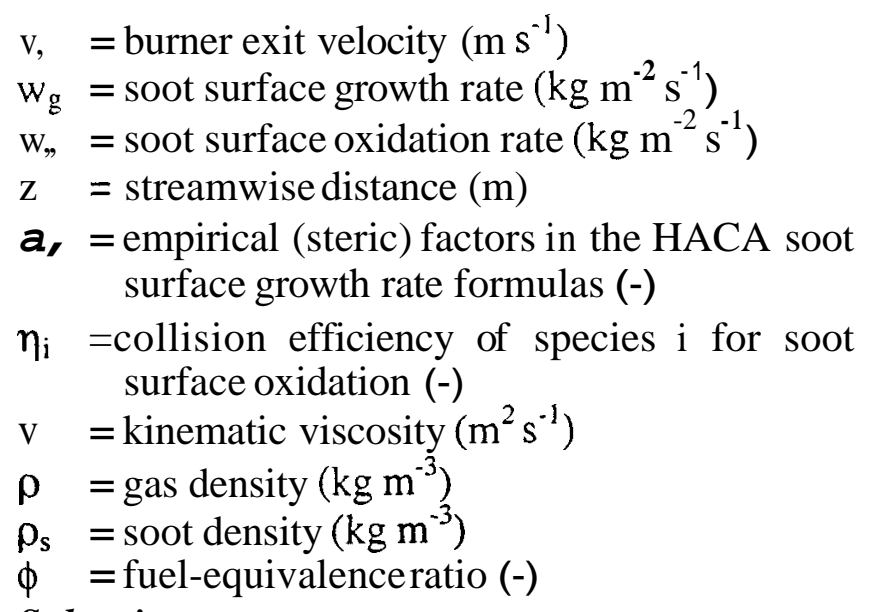

Subscripts

$\mathrm{CH}=\mathrm{HACA}$ soot surface growth mechanism of Colket and Hall [18]

FW $=$ HACA soot surface growth mechanism of Frenklach and coworkers[19-21]

\section{INTRODUCTION}

Soot is a major unsolved combustion problem because it is present in most hydrocarbon-fueled nonpremixed (diffusion) flames and current understanding of soot processes in flame environments is limited. This lack of understanding limits progress toward developing reliable methods of computational combustion, predictions of pollutant emission properties and estimates of flame radiation properties, among others. Motivated by these observations, the present investigation sought to extend earlier studies of soot processes in laminar premixed and diffusion flames completed in this laboratory [19], using similar methods. The specific objectives of the present investigation were to obtain new experimental information about the flame structure, and the soot structure and surface reaction properties, of round laminar jet diffusion flames burning acetylene-nitrogen mixtures in coflowing air at pressures of 0.125-1.000 atm with the reactants at normal temperature. The following description of the research is brief; more details are provided by $\mathrm{Xu}[10]$ and $\mathrm{El}$ Leathy [11].

Early studies of the structure and soot surface reaction properties of laminar flames have been reviewed by Haynes and Wagner [12], Howard [13], Richter and Howard [14] and Kennedy [15]; therefore, the following discussion of earlier work will be brief and will emphasize past studies in this laboratory that have motivated the objectives and methods of the present investigation. Sunderland and coworkers [1-31 experimentally studied the structure and soot surface growth properties of laminar hydrocarbon-fueled (acetylene, ethane, propane, n-butane, propylene and 1,3-butadiene) diffusion flames burning in air at pressures of $10-100 \mathrm{kPa}$, however, they were not able to evaluate available mechanisms of soot surface growth because their measurements did not provide information about $\mathrm{H}$ concentrations needed by the theories. $\mathrm{Xu}$ and coworkers [4-7] subsequently completed experimental investigations of the structure and soot surface growth properties of laminar premixed flames at atmospheric pressure including ethylene/air mixtures similar to the flames studied by Harris and Weiner [16] and methane/oxygen mixtures similar to the flames studied by Ramer et al. [17]. Concentrations of $\mathrm{H}$ were found during these studies so that the measurements could be used to evaluated the Hydrogen-Abstraction/Carbon-Addition (HACA) soot surface growth mechanisms of Colket and Hall [18] and Frenklach and coworkers [19-21]. It was found that the HACA soot surface growth mechanisms provided excellent correlations of the measurements using quite reasonable values of unknown empirical steric factors that appear in the theories. $\mathrm{Xu}$ and Faeth [7] and El-Leathy [8] extended the study of soot surface growth from premixed flames to hydrocarbon-fueled laminarjet diffusion flames (involving acetylene, ethylene, propylene and benzene fueled flames) burning in air at atmospheric pressure, using the full suite of measurements developed during the laminar premixed flame studies of Refs. 4-6. These results showed that soot surface growth rates in laminar premixed and diffusion flames satisfied similar reaction rate expressions, that there were little effects of hydrocarbon fuel type

\section{American Institute of Aeronautics and Astronautics}


on soot surface growth rates, and that soot surface growth rates were well represented by the HACA mechanisms of Colket and Hall [18] and Frenklach and coworkers [19-21].

Finally, $\mathrm{Xu}$ et al. [8] established that soot surface oxidation in laminar diffusion flames at atmospheric pressure for fuel-rich and near stoichiometric conditions and involving a variety of hydrocarbon fuels (acetylene, ethylene, propylene, propane and benzene), was dominated by the reaction of the soot surface with $\mathrm{OH}$, and could be correlated effectively by estimating the oxidation rate due to $\mathrm{O}_{2}$ using the classical expression of Nagle and Strickland-Constable [22] (whose results were confirmed later by Park and Appleton [23]) combined with an oxidation rate due to $\mathrm{OH}$ that had very nearly the same collision efficiency as the results of Neoh and coworkers [24-26] based on measurements in soot containing premixed flames at atmospheric pressure. This finding is also in fair agreement with earlier measurements of soot surface oxidation rates by $\mathrm{OH}$ in diffusion flames at atmospheric pressure due to Garo et al. [27-28] and Hardiquert et al. [29]. Naturally there have been many other studies of the structure and soot reaction processes of laminar hydrocarbon-fueled diffusion flames seeking detailed models of their properties, see El-Leathy et al. [9] for descriptions of these studies.

Based on the current status of understanding of the structure and soot surface reaction properties of laminar flames, the present investigation sought to extend this work by experimentally studying coflowing laminar jet diffusion flames burning in air at subatmospheric pressures (0.125-1.000 atm). This was done recognizing that past expressions for soot surface growth and oxidation rates had only involved the concentrations of reactants, and did not involve pressure explicitly, because pressure variations involve broader ranges of concentrations then considered earlier, which could open up new channels for soot surface growth and oxidation. Because effects of fuel type had been studied extensively during earlier work, see Refs. 1-11. and had not been found to be important, the present investigation was limited to acetylenefueled laminar jet diffusion flames burning in coflowing air.

To summarize, the specific objectives of the present study were as follows: (1) to measure the structure (temperatures, stable and radical species concentrations, velocities) and soot properties (soot volume fractions and primary soot particle diameters) within the soot containing region of acetylene-fueled laminar jet diffusion flames burning in air at pressures of 0.125-1.000 atm, and (2) to exploit the new measurements along with existing measurements in laminar premixed [4-6] and diffusion flames [7-9] at atmospheric pressure, to evaluate and correlate the HACA soot surface growth mechanisms of Colket and Hall [18] and Frenklach and coworkers [19-21], and the $\mathrm{OH} / \mathrm{O}_{2}$ soot surface oxidation mechanisms of Neoh and coworkers [24-26] and Nagle and Strickland-Constable[22]. The study was limited to measurements along the axes of buoyant laminar jet diffusion flames burning in coflowing air at various subatmospheric and atmospheric pressures, using methods developed during earlier studies of soot processes in laminar diffusion flames in this laboratory due to Sunderland and coworkers [1-3] and $\mathrm{Xu}$ and coworkers [7-9].

\section{'ERIMEN METHODS}

Apparatus

The test arrangement was similar to the arrangement used by Sunderland and coworkers $[1,2]$ for measurements of the structure and soot properties of laminar jet diffusion flames at subatmospheric pressures. A sketch of the apparatus appears in Fig. 1. The arrangement consisted of a round fuel jet having a diameter of $3.3 \mathrm{~mm}$, injecting vertically upward and surrounded by a slow concentric flow of air. The flames burned along the axis of a vertical windowed cylindrical chamber having a diameter and length of $300 \mathrm{~mm}$. The top and bottom of the chamber consisted of porous metal plates that 
separated the flame chamber from plenum chambers for air inflow and exhaust outflow and provided a uniform distribution of air flow over the flame chamber cross section. The fuel and air flows were measured with rotameters calibrated in turn by wet-test meters, whereas the exhaust flow was removed using a vacuum pump. The flames were ignited by a hot-wire that could be retracted from the burner exit once ignition was complete. The entire test chamber could be traversed in the vertical and horizontal directions in order to accommodate rigidly mounted optical instruments.

\section{Instrumentation}

Present measurements were similar to $\mathrm{Xu}$ and Faeth [7] and El-Leathy et al. [9] and included the following properties measured along the axes of the flames: soot volume fractions, flame temperatures, concentrations of major stable gas species, soot structure, gas velocities and concentrations of some radical species $(\mathrm{H}, \mathrm{OH}$, and $\mathbf{O}$ ).

Soot volume fractions were measured by deconvoluting laser extinction measurements at $632.8 \mathrm{~nm}$ for chord-like paths through the flames. Data was reduced using the refractive indices of Dalzell and Sarofim [30], similar to past work [111]; these values have recently been confirmed by Krishnan et al. [31]. The experimental uncertainties (95\% confidence) of soot volume fractions are estimated to be smaller than $10 \%$ for soot volume fractions greater than $0.02 \mathrm{ppm}$, increasing inversely proportional to the soot volume fraction for smaller values.

Soot and gas temperatures are essentially the same $[7,8]$; thus soot (gas) temperatures were measured by deconvoluting spectral radiation intensities for chord-like paths through the flames and computing temperatures at several wavelength pairs $(550 / 700,550 / 750,550 / 830$. $600 / 700,600 / 750,600 / 830$, and 650/750 nm). Temperature differences between the average and any of the line pairs were less than 50-100 K and experimental uncertainties (95\% confidence) of these measurements were less than $50 \mathrm{~K}$ ).

Concentrations of major gas species $\left(\mathrm{N}_{2}, \mathrm{Ar}\right.$, $\mathrm{H}_{2} \mathrm{O}, \mathrm{H}_{2}, \mathrm{O}_{2}, \mathrm{CO}, \mathrm{CO}_{2}, \mathrm{CH}_{4}, \mathrm{C}_{2} \mathrm{H}_{2}, \mathrm{C}_{2} \mathrm{H}_{4}, \mathrm{C}_{3} \mathrm{H}_{6}$, $\mathrm{C}_{3} \mathrm{H}_{8}, \mathrm{C}_{6} \mathrm{H}_{6}$ and neon, (the last being a tracer gas used to estimate effects of radial diffusion of lithium-containing species that were used to'find $\mathrm{H}$ concentrations) were measured by sampling and analysis by gas chromatography. Experimental uncertainties (95\% confidence) of these measurements are mainly due to calibration uncertainties and are estimated to be less than $5 \%$ for all species concentrations reported here.

Soot structure measurements were limited to primary soot particle diameters carried out by thermophoretic sampling and analysis using Transmission Electron Microscopy (TEM), following Dobbins and Megaridis [32] similar to earlier work in this laboratory [I-111. Primary particle diameters were nearly monodisperse at given positions in each flame (standard deviations were less than $10 \%$ ) and the experimental uncertainties (95\% confidence) of soot primary particle diameter measurements are estimated to be less than $10 \%$.

Streamwise gas velocities were measured using laser velocimetry (LV) with experimental uncertainties (95\% confidence) less than $5 \%$.

Measurements of $\mathrm{H}$ concentrations were carried out by deconvoluted absorption following the $\mathrm{Li} / \mathrm{LiOH}$ atomic absorption technique of Neoh and coworkers [24-26]. Correction for the radial diffusion of $\mathrm{LiOH}$ seed was found from measurements of the concentrations of neon seed, assuming that the diffusivities of $\mathrm{LiOH}$ and neon were similar. The $\mathrm{H}$ concentration measurements were calibrated using a premixed flame as discussed by $\mathrm{Xu}$ and Faeth [6] and similar to Neoh and coworkers [24-26]. Measurements with different seeding levels showed that effects of the $\mathrm{LiOH}$ seed on flame properties were negligible, similar to past work $[7,8]$. Experimental uncertainties (95\% confidence) of the $\mathrm{H}$ concentration measurements are estimated to be smaller than $30 \%$. 


\section{Test Conditions}

The properties of the laminar premixed flame used to calibrate the $\mathrm{H}$ concentration measurements are reported by Xu and Faeth [6]. Test conditions for all the diffusion flames considered during the present study are summarized in Table 1. These flames all involved acetylene as the fuel, burning in coflowing air at pressures of $0.125-1.000 \mathrm{~atm}$. Nitrogen dilution of the fuel stream was used for flames at pressures of $0.5 \mathrm{~atm}$ and higher in order to keep maximum soot volume fractions smaller than $2 \mathrm{ppm}$ so that problems of large soot concentrations on the measurements could be avoided. Stoichiometric flame lengths (the vertical height of the position along the axis where the local fuel-equivalence ratio was stoichiometric) were $25-41 \mathrm{~mm}$ whereas luminous flame lengths (due to yellow light emitted from heated soot particles) were all 50 $\mathrm{mm}$; therefore soot particles passed into the fuel lean region of the present flames where soot oxidation was completed. All the flames were well attached, stationary and laminar over the region where measurements were made.

\section{Soot Structure}

\section{RESULTS AND DISCUSSION}

TEM photographs of typical soot particles in the four test flames, each obtained at the end of the soot formation region where the soot volume fraction is a maximum, are illustrated in Fig. 2. Soot particle images at other locations and for other flames are qualitatively the same and were generally similar to TEM images of soot particles obtained in other premixed and diffusion flames that have been studied, see Refs. 1-11 and references cited therein. In general, soot particles consist of roughly spherical primary soot particles that have nearly constant diameters at a particular flame condition, collected into aggregates that are known to be mass fractal objects $[31,33]$. The mean number of primary soot particles per aggregate increased with increasing distance from the burner exit, similar to the measurements of this property due to
Sunderland et al. [1].

\section{Flame Structure}

Measurements of gas (soot) temperatures. streamwise gas velocities, soot volume fractions. primary soot particle diameters, concentrations of major gas species and concentrations of radical species $(\mathrm{H}, \mathrm{OH}$, and $\mathrm{O})$ are plotted as a function of the distance along the flame axis for the four test flames in Figs. 3-6. Corresponding residence times, found by integrating the velocity measurements, are indicated at the top of the plots. The residence times are relative to the first position where detectable soot volume fractions were observed (at $\mathrm{z}=5-20 \mathrm{~mm}$ for the four flames). The stoichiometric $(\phi=1)$, or flame sheet condition for the four flames are at $\mathrm{z}$ $=25-41 \mathrm{~mm}$ and are marked on each figure. Luminous flame length are all at $\mathrm{z}=50 \mathrm{~mm}$ and are near the right hand boundaries of the figures for all the flames. These positions also correspond to the location farthest from the burner exit where finite soot volume fractions could be measured.

Gas (soot) temperatures along the flame axes in Figs. 3-6 reach a maximum well before the maximum soot concentration and flame sheet conditions are reached. This behavior is similar to other soot-containing laminar jet diffusion flames that have been studied in this laboratory and is caused by continuum radiation heat losses from soot [1-3, 7-9].

The present burner has a relatively small fuel port diameter whereas luminous flame lengths are $50 \mathrm{~mm}$ which are comparable to earlier diffusion flames that have been studied by Sunderland and coworkers [1-3] and $\mathrm{Xu}$ and coworkers $[8,9]$. As a result, velocities near the burner exit are relatively large, $2.5-12 \mathrm{~m} / \mathrm{s}$, so that velocities along the flame axis decrease with increasing distance from the burner exit, in spite of effects of buoyancy.

Similar to earlier observations of sootcontaining laminar jet diffusion flames in this laboratory, Refs. 1-3, 7 and 8, primary soot particle diameters reach maximum values 
relatively early in the soot formation region. This behavior is caused by accelerating primary soot particle nucleation rates with increasing streamwise distance in the initial portions of the soot formation region, which is caused by progressively increasing $\mathrm{H}$ concentrations with increasing streamwise distance, see $\mathrm{Xu}$ and coworkers [7, 8]. This behavior causes the relatively few primary soot particles formed near soot inception conditions, that become large due to long periods of soot surface growth, to be superseded by the much larger number of primary soot particles formed later in the soot formation region that are smaller due to shorter periods of soot surface growth. This behavior is aided by the fact that rates of soot surface growth remain relatively rapid near soot inception conditions, as noted by Tesner [34, 35], which allows the relatively few primary particles present there to grow quite large.

Significant levels of soot formation (evidenced by the appearance of measurable soot concentrations), were generally associated with the first streamwise locations where detectable concentrations of $\mathrm{H}$ were observed, because acetylene, the other reactant of the HACA soot surface growth mechanisms, was always present near the burner for the present acetylene-fueled flames, see Figs. 3-6. Soot formation (as indicated by soot surface growth) became small again where maximum soot volume fractions were reached; which occurred in the presence of relatively large concentrations of $\mathrm{H}$ but where acetylene concentrations became smaller than roughly $0.1 \%$ by volume. This behavior was also similar to other soot containing laminar jet diffusion flames that have been studied in this laboratory, see Refs. 1-3,7 and 8.

The concentrations of major stable gas species in Figs. 3-6 are similar to the concentrations of major stable gas species in other laminar flames burning in air, involving acetylene and other hydrocarbons as fuels, see Refs. 1-3,7 and 8. If the original fuel is not acetylene (see Refs. 7 and 8), however, decomposition of the original fuel yields significant concentrations of acetylene near the burner exit as well. As a result, concentrations of acetylene within flames fueled with hydrocarbons other than acetylene are generally quite similar to acetylene concentrations within acetylene-fueled flames. One difference concerning fuel type, however, is that benzene is only observed as a stable gas species in flames involving benzene as a fuel; benzene was sought but was not found in detectable concentrations in the other flames (where benzene was the fuel, benzene concentrations in the soot-containing portion of the flame were relatively small, less than 1 percent by volume, and did not vary significantly over the soot containing regime except for its final disappearance near the flame sheet with the other gaseous hydrocarbon species). As the flame sheet is approached, concentrations of hydrocarbon species decrease, concentrations of the main combustion products $\left(\mathrm{CO}_{2}\right.$ and $\left.\mathrm{H}_{2} \mathrm{O}\right)$ reach broad maxima, whereas concentrations of $\mathrm{O}_{2}$ either remain nearly constant at the lower pressures (0.125-0.500 atm) at values near 1-2 percent by volume, or gradually increase in the range $0.01-1$ percent by volume (at $1.000 \mathrm{~atm}$ ). Finally, nitrogen concentrations remain nearly uniform except near the burner exit at low pressures where nitrogen concentrations decrease noticeably because there is no nitrogen in the fuel stream.

Concentrations of $\mathrm{H}, \mathrm{OH}$ and $\mathrm{O}$ all increases as the flame sheet is approached for the flames at higher pressures (0.500 and $1.000 \mathrm{~atm})$, however, radical concentrations (particularly $\mathrm{H}$ and $\mathrm{OH}$ are relatively constant for the flames at lower pressures (0.125 and 0.250 atm). Maximum concentrations of $\mathrm{H}$ are roughly 0.01 percent by volume, maximum concentrations of $\mathrm{OH}$ are roughly 0.001 percent by volume, whereas maximum concentration of $\mathbf{O}$ are significantly smaller, 0.0001-0.000001 percent by volume.

The region where soot is present in Figs. 3-6 contains appreciable concentrations of species potentially responsible for soot oxidation, e.g., $\mathrm{O}_{2}$,

6

American Institute of Aeronautics and Astronautics 
$\mathrm{CO}_{2}, \mathrm{H}_{2} \mathrm{O}$ and $\mathrm{OH}$ [22-29, 36-39] with the exception of $\mathrm{O}$ which has rather small concentrations as just noted. In particular, $\mathrm{O}_{2}$ is usually present at concentrations on the order of 1 percent (by volume) throughout most of the soot surface growth region of the present laminar coflowing jet diffusion flames; which is somewhat larger than $\mathrm{O}_{2}$ concentrations observed in other soot containing diffusion flames having larger burner diameters at atmospheric pressure (and thus much smaller flow velocities). The present behavior could be due to a greater propensity for $\mathrm{O}_{2}$ leakage though the base of the present flames due to their smaller burner diameters and larger velocities.

Computed mixture fractions and superequilibrium ratios of $\mathrm{H}, \mathrm{OH}$ and $\mathrm{O}$ along the axes of the four test flames are illustrated in Fig. 7. The superequilibrium ratios were found from the temperatures and compositions measured within the flames, given the equilibrium constant data of Chase et al. [40]. Present flames having large velocities, short residence times and generally larger temperatures due to reduced radiation heat losses (due to the smaller residence times) generally exhibit smaller superequilibrium ratios than the earlier measurements of superequilibrium ratios in soot-containing diffusion flames of $\mathrm{Xu}$ and coworkers [7-9]. These differences come about, however, mainly due to the increased temperature of the present flames which increases the degree of dissociation of the flame gases and thus the equilibrium concentrations of $\mathrm{H}, \mathrm{OH}$ and $\mathrm{O}$ (recall that the radical concentrations of the present flames also are somewhat smaller that those of the flames considered by $\mathrm{Xu}$ and coworkers [7-9]). Thus, maximum superequilibrium ratios of the present flames barely approach unity whereas these ratios reached values of 10-20 for the flames of Refs. 79.

\section{Soot Surface Reaction Rate Properties}

Past measurements of laminar premixed and diffusion flames were used to study soot surface growth and oxidation. Major assumptions were as follows: soot surface growth, rather than soot nucleation, dominates soot mass production; soot surface oxidation dominates soot oxidation; effects of diffusion (Brownian motion) and thermophoresis on soot motion are small, so that soot particles convect along the axes of the flames at the local gas velocity; the soot density is constant; and the surface area available for soot surface growth and oxidation is equivalent to constant diameter spherical primary soot particles that meet at a point. See Refs. 1-9 for justification of these assumptions.

The first soot formation property of importance is the number of primary particles per unit volume, found from the measured soot volume fractions and primary soot particle diameters, as follows $[\mathrm{I}]$ :

$\mathrm{n}_{\mathrm{p}}=6 \mathrm{f}_{\mathrm{s}} /\left(\pi \mathrm{d}_{\mathrm{p}}^{3}\right)$

The experimental uncertainties (95\%) confidence of $n_{p}$ are estimated to be less than $32 \%$ for $f_{s} \geq 0.1 \mathrm{ppm}$, increasing inversely proportional to $f_{s}$ for smaller values of $f$,. The soot surface area per unit volume is given by the same measurements, as follows [1]:

$\mathrm{S}=6 \mathrm{f}_{\mathrm{s}} / \mathrm{d}_{\mathrm{p}}$

The experimental uncertainties (95\% confidence) of $\mathrm{S}$ are estimated to be less than $16 \%$ for $f_{s} \geq 0.1 \mathrm{ppm}$, increasing inversely proportional to $f_{s}$ for smaller values of $f_{s}$. Defining the soot surface growth rate as the rate of increase of soot mass per unit surface area and time, and the soot surface oxidation rate as the rate of decrease of soot mass per unit surface area and time, conservation of soot mass along a stream line under the previous assumptions gives the soot surface growth and oxidation rates, as follows [1]:

$w_{g}=-w_{o x}=(\rho / S) d\left(\rho_{s} f_{s} / \rho\right) / d t$

where present measurements of species 
concentrations and temperatures yield the gas density, assuming an ideal gas mixture, and the minus sign is inserted so that $\mathrm{w}_{\mathrm{ox}}$ is a positive number. The temporal derivative in Eq. 3 was found from three-point least-squares fits of the argument of the derivative, similar to past work. The soot density in Eq. 3 was taken to be equal to $1850 \mathrm{~kg} / \mathrm{m}^{3}$, similar to past work [1-8]. Finally, consideration of soot surface oxidation was limited to early soot oxidation (soot mass consumption less than $70 \%$ ) where problems of soot aggregate breakup, the development of primary soot particle porosity, and internal oxidation of primary soot particles, do not yet occur, see Neoh et al [26]. Estimated experimental uncertainties (95\% confidence) of soot surface growth rates are less than $\mathbf{3 0} \%$; estimated experimental uncertainties of soot surface oxidation rates are comparable.

\section{Soot Surface Growth Rates}

Gross soot surface growth rates for all the premixed and diffusion flames considered during the present investigation were corrected for effects of soot surface oxidation because soot surface growth and oxidation proceed at the same time, as noted in connection with Figs. 3-6. The correction for soot surface oxidation was done in the same way as Ref. 8, using the results of $\mathrm{Xu}$ et al. [8] concerning soot oxidation in laminar diffusion flames. Thus, it was assumed that soot surface oxidation was dominated by the $\mathrm{OH}$ oxidation mechanism, after allowing for direct soot surface oxidation by $\mathrm{O}_{2}$ based on the mechanism of Nagle and Strickland-Constable [22]. It was found that effects of corrected soot surface growth rates in this way were small, except when soot surface growth rates themselves became small toward the end of the soot formation region. Thus, in order to be conservative about potential effects of soot surface oxidation, determination of soot surface growth rates, corrected for effects of soot surface oxidation, were limited to conditions where estimated soot surface oxidation rates never exceeded half the gross soot growth rates, similar to past work [1-91.

Soot surface growth rates were interpreted using the HACA soot growth mechanisms of Colket and Hall [18] and Frenklach and coworkers [19-21], in order to maintain consistency with past evaluations of these mechanisms based on similar measurements and due to the success of these approaches for correlating measurements of soot surface growth in premixed ethylene/air and methane/oxygen flames. In all cases, net soot surface growth rates were expressed, as follows:

$w_{g}=\alpha_{i} R_{i}$

where $\mathrm{i}=\mathrm{CH}$ or FW denotes reaction parameters for the HACA soot surface growth rate mechanisms of Colket and Hall [18] and Frenklach and coworkers [19-21], which were found from the measurements. The details of these mechanisms, the formulas for the $R_{i}$, and the reaction-rate parameters for the $R_{i}$ can be found in $\mathrm{Xu}$ et al. [4]. The parameters, $\alpha_{\mathrm{i}}$ are empirical steric factors on order of unity, $\alpha_{\mathrm{CH}}$ specified to be a constant [18] and $\alpha_{F W}$ specified to be a function of temperature.

A direct evaluation of the HACA mechanisms of soot surface growth is obtained by plotting $\mathrm{w}_{\mathrm{g}}$ as a function of $\mathrm{R}_{\mathrm{CH}}$ for the Colket and Hall [18] mechanism. These results for the Frenklach and coworkers [19-21] mechanism are discussed by El-Leathy [11]. The results for the Colket and Hall [18] mechanism are illustrated in Fig. 8. In this figure, available measurements for both premixed and diffusion flames (after correcting all measurements for soot surface oxidation) are illustrated along with best-fit correlation for all the flames. The corresponding steric factor and its experimental uncertainties (95\% confidence) is 1.0 with an uncertainty of 0.2 . It is encouraging that the steric factor is of order of magnitude unity, as expected. The correlation for the diffusion flames and all the flames is essentially the same. Correlated values of soot 
surface growth rates for the premixed flames are slightly lower than for the diffusion flames (possibly because estimates of $\mathrm{H}$ concentrations are based on the assumption of local equilibrium of $\mathrm{H}$, which is somewhat larger than the measurements, were used for the premixed flames), but the differences are comparable to present experimental uncertainties. Considering the results for the diffusion flames alone, there clearly is no difference between estimates of $\mathrm{w}_{\mathrm{g}}$ based on the HACA mechanisms as the hydrocarbon fuel type is varied. The behavior using the HACA mechanism of Frenklach and coworkers [19-21], see El-Leathy [11], is essentially the same. Naturally, these findings are also consistent with the onset of soot formation occurring when $[\mathrm{H}]$ first appears in the presence of significant acetylene concentrations on the burner side of the soot formation region and the end of soot formation occurring when acetylene subsequently disappears in the presence of significant $\mathrm{H}$.

\section{Soot Surface Oxidation Rates}

Present measurements of soot surface oxidation rates were corrected for effects of soot surface growth based on the Colket and Hall [18] soot surface growth mechanism, correlated as just described. No condition is considered in the following, however, where the correction for soot surface growth was more than half the gross soot surface oxidation rate.

Similar to Neoh et al. [25] present soot surface oxidation rates (corrected for soot surface growth) were converted into collision efficiencies based on kinetic theory estimates of the collision rates of a given gas species with the surface of primary soot particles. Thus, the collision efficiency for a potential oxidizing species is given by the following expression [2]:

$\eta_{i}=4 w_{o x} /\left(C_{i}[i] \bar{v}_{i}\right)$

where $C_{i}$ is the mass of carbon removed from the surface per mole of species $i$ reacting at the surface, [i] is the gas phase concentration of $i$ adjacent to the surface, and

$$
\overline{\mathrm{v}}_{\mathrm{i}}=\left(8 \mathrm{kT} /\left(\pi \mathrm{m}_{\mathrm{i}}\right)\right)^{1 / 2}
$$

is the (Boltzmann) equilibrium mean molecular velocity of species i. Values of $\eta_{i}$ were measured for potential soot surface oxidation for $\mathrm{i}=\mathrm{O}_{2}, \mathrm{CO}_{2}, \mathrm{H}_{2} \mathrm{O}, \mathrm{O}$ and $\mathrm{OH}$.

The collision efficiencies of $\mathrm{O}_{2}$ for soot surface oxidation are plotted as a function of height above the burner in Fig. 9. Results shown on the figure include the range of values observed by Neoh et al. [25] in premixed flames, the values measured by $\mathrm{Xu}$ et al [8] in diffusion flames, and values estimated from the predictions of Nagle and Strickland-Constable [22] for conditions in the diffusion flames considered by $\mathrm{Xu}$ et al. [8]. The Nagle and StricklandConstable [22] approach has exhibited effective capabilities to predict soot surface oxidation by $\mathrm{O}_{2}$, see Park and Appleton [23] and references cited therein, and there are significant concentrations of $\mathrm{O}_{2}$ for soot paths along the axes of the diffusion flames, see Figs. 3-6. Thus, the fact that the Nagle and Strickland-Constable [22] estimates of the $\mathrm{O}_{2}$ collision efficiency are 10100 times smaller than the measurements in diffusion flames, strongly suggests that some other species is mainly responsible for soot surface oxidation in the diffusion flames. Other evidence that $\mathrm{O}_{2}$ is not the main direct oxidizing species for flame environments is provided by the large scatter (nearly a factor of 100) of the collision efficiencies for the diffusion flames, combined with the even larger scatter (more than a factor of 100) of the collision efficiencies of Neoh et al. [25] for premixed flames.

The collision efficiencies for $\mathrm{CO}_{2}, \mathrm{H}_{2} \mathrm{O}$, and $\mathrm{O}$ yielded similar conclusions to that for $\mathrm{O}_{2}$; namely, it is unlikely that these species are major contributions to soot surface oxidation in flames, either alone or in parallel with soot oxidation by $\mathrm{O}_{2}$.

Finally, the collision efficiencies of $\mathrm{OH}$ for 
soot surface oxidation are plotted as a function of height above the burner in Fig. 10. With perhaps one exception (at an extreme condition where experimental uncertainties are relatively large), direct $\mathrm{O}_{2}$ surface oxidation of soot is not very important for these conditions, as before. On the other hand, similar to the observations of Neoh et al. [25], collision efficiencies for $\mathrm{OH}$ for the diffusion flames exhibit relatively small degrees of scatter (roughly a factor of 3 ) and are in excellent agreement with the results of Neoh et al. [25] for premixed flames. In particular, the mean collision efficiency of $\mathrm{OH}$ for soot surface oxidation in the diffusion flames is 0.10 with a standard deviation of 0.07 which is in excellent agreement with the value of 0.13 found by Neoh et al. [25] for soot surface oxidation in premixed flames using the same treatment of soot structure as the present investigation. Finally, this agreement was achieved over a relatively broad range of flame conditions for the combined results in premixed and diffusion flames as follows: temperatures of 1570-1870 K, oxygen mole fractions of $1 \times 10^{-5}-1.2 \times 10^{-2}$, and levels of soot mass consumption less than $70 \%$ at atmospheric pressure for flames fueled with a variety of fuels. Although these results are helpful, however, the properties of the final stage of oxidation, where internal oxidation of primary soot particles becomes a factor, effects of pressure on soot oxidation, and possibly effects of fuel type on soot oxidation for hydrocarbons other than those considered here, all merit additional study in the future. In particular, the measurements of the present test flames, once confirmed, should allow examination of effects of pressure on soot surface oxidation-at least for subatmospheric conditions.

\section{CONCLUSIONS}

Flame structure and soot surface growth and oxidation rates were studied for coflowing laminar jet diffusion flames emphasizing new measurements of flame structure at subatmospheric and atmospheric pressures (0.125-1.000 atm). Assessments of soot surface growth and oxidation rate properties were limited to earlier measurements at atmospheric pressure, pending confirmation of the structure measurements and reduction to find appropriately corrected surface reaction rates at subatmospheric pressures. Surface reaction rate properties that were considered, however, involved a variety of hydrocarbons (acetylene, ethylene, propylene, propane, benzene and methane) in both laminar premixed and diffusion flames. The major conclusions of the study are as follows:

1. Laminar diffusion flames at subatmospheric pressures were qualitatively similar to those at atmospheric pressure. The main difference was that present flames had small injector diameters so that flame residence times were small and radiation heat losses were reduced. This resulted in somewhat smaller concentrations of $\mathrm{H}$, $\mathrm{OH}$ and $\mathrm{O}$ in the soot containing region and significantly reduced superequilibrium ratios for these radicals due to large degrees of dissociation resulting at equilibrium conditions due to the larger flame temperatures.

2. Soot surface growth rates in laminar diffusion and premixed flames, for various fuel types in both types of flame, agree within experimental uncertainties at comparable local conditions and could be correlated reasonably well by the HACA soot surface growth mechanisms of Colket and Hall [18] and Frenklach and coworkers [19-21] with steric factors in both these mechanisms having values on the order of unity, as expected.

3. Soot surface oxidation rates in the laminar diffusion flames for various fuel types, could be correlated by assuming a constant collision efficiency for $\mathrm{OH}$ for soot surface oxidation of 0.10 with a standard deviation of 0.07 . This finding is in good agreement with the $\mathrm{OH}$ collision efficiency for soot surface oxidation of 0.13 for assumed similar soot structure properties found by Neoh et al. [25] for measurements in 
premixed flames at atmospheric pressure at similar $\mathrm{O}_{2}$ concentrations. The correction of present soot surface oxidation rates for oxidation by $\mathrm{O}_{2}$ based on the results of Nagle and Strickland-Constable [22] was small (on average less than $10 \%$ ) compared to soot surface oxidation by $\mathrm{OH}$ for present conditions.

It should be recalled, however, that present results concerning soot surface reaction properties were limited to measurements of flames at atmospheric pressure. Current work is seeking to confirm the new structure measurements and to reduce the surface reaction rate results, and appropriately correct them for effects soot surface oxidation and growth, as needed, so that the evaluation can be extended to consider the important effect of pressure of soot surface reaction rates.

\section{REFERENCES}

1. Sunderland, P.B., Köylü, Ü.Ö., and Faeth, G.M., "Soot Formation in Weakly Buoyant Acetylene-Fueled Laminar Jet Diffusion Flames Burning in Air," Combustion and Flame, Vol. 100 Nos. 1/2. 1995,pp. 310-322.

2. Sunderland, P.B., and Faeth, G.M., "Soot Formation in Hydrocarbon/Air Laminar Jet Diffusion Flames," Combustion and Flame, Vol. 105 Nos. 1/2. 1996, pp. 132-146.

3. Lin, K.-C., Sunderland, P.B., and Faeth, G.M., "Soot Nucleation and Growth in Acetylene/Air Laminar Coflowing Jet Diffusion Flames," Combustion and Flame, Vol. 104 No. 3. 1995, pp. 369-375, 1996.

4. Xu, F. Sunderland, P.B., and Faeth, G.M., "Soot Formation in Laminar Premixed Methane/Oxygen Flames at Atmospheric Pressure," Combustion and Flame, Vol. 108 No. 4 1997,pp. 471-493.

5. Xu, F., Lin, K.-C., and Faeth, G.M., "Soot Formation in Laminar Premixed Methane/Oxygen Flames at Atmospheric Pressure," Combustion and Flame, Vol. 115 Nos. 1/2. 1998,pp. 195-209.

6. Xu, F., and Faeth, G.M., "Structure of the Soot
Growth Region of Laminar Premixed Methane/Oxygen Flames," Combustion and Flame, Vol. 121 No. 4. 2000, pp. 640-650.

7. Xu, F., and Faeth, G.M. "Soot Formation in Laminar Acetylene/Air Diffusion Flames at Atmospheric Pressure," Combustion and Flame, Vol. 125 Nos. 1/2. 2001, pp. 804-819.

8. Xu, F., El-Leathy, A.M., Kim, C.H., and Faeth G.M., "Soot Surface Oxidation in Hydrocarbon/Air Diffusion Flames at Atmospheric Pressure," Combustion and Flame, in press.

9. El-Leathy, A.M., Xu, F., Kim, C.H., and Faeth G.M., "Soot Surface Growth in Laminar Hydrocarbon/Air Diffusion Flames," AZAA Journal, in press.

10. Xu, F., Soot Growth in Laminar Premixed Flames, Ph. D. Dissertation, Department of Aerospace Engineering, The University of Michigan, Ann Arbor, 1999.

11.El-Leathy, A.M., Effect of Hydrocarbon Fuel on Soot Surface Growth and Oxidation in Laminar Diffusion Flames, Ph. D. Dissertation, Mechanical Power Department, Helwan University, Cairo, 2002.

12. Haynes, B.S., and Wagner, H.G., "Soot Formation," Progress in Energy and Combustion Science, Vol. 7, No. 4, 1981, pp. 229-273.

13. Howard, J.B., "Carbon Addition and Oxidation Reactions in Heterogeneous Combustion and Soot Formation," Proceedings of the Combustion Institute, Vol. 23, 1990, pp. 1107-1127.

14. Richter, W., and Howard, J.B., "Formation of Polycyclic Aromatic Hydrocarbons and Their Growth to Soot-A Review of Chemical Reaction Pathways," Progress in Energy and Combustion Science, Vol. 26, Nos. 4-6, 2000, pp. 565-608.

15. Kennedy, I.M., "Models of Soot Formation and Oxidation," Progress in Energy and Combustion Science, Vol. 23, No. 2, 1981, pp. 95-132.

16. Harris, S.J., and Weiner, A.M., "Surface 
Growth of Soot Particles in Premixed Ethylene/Air Flames," Combustion Science and Technology, Vol. 31, Nos. 3 and 4, 1983, pp. 155-167.

17. Ramer, E.R., Merklin, J.F., Sorensen, C.M., and Taylor, T.W., "Chemical and Optical Probing of Premixed Methane/Oxygen Flames," Combustion Science and Technology, Vol. 48, Nos. 5 and 6, 1986,pp. 241-255.

18. Colket, M.B., and Hall, R.J., "Successes and Uncertainties in Modeling Soot Formation in Laminar Premixed Flames," Soot Formation in Combustion (H. Bockhorn, ed.), SpringerVerlag, Berlin, 1994,pp. 442-470.

19. Frenklach, M., and Wang, H., "Detailed Modeling of Soot Particle Nucleation and Growth," Proceedings of the Combustion Institute, Vol. 23, 1990, pp. 1559-1566.

20. Frenklach, M., and Wang, H., Soot Formation in Combustion (H. Bockhorn, ed.), SpringerVerlag, Berlin, 1994, pp.165-192.

21. Kazakov, A., Wang, H., and Frenklach, M., "Detailed Modeling of Soot Formation in Laminar Premixed Ethylene Flames at a Pressure of 10 Par," Combustion and Flame, Vol. 100, Nos. 1/2, 1995, pp. 111-120.

22. Nagle, J. and Strickland-Constable, R.F., "Oxidation of Carbon Between 1000-2000 C,"

Proceedings of Fifth Carbon Conference, Vol. 1, 1962, 00. 154-164.

23. Park, C., and Appleton, J.P., "Shock-Tube Measurements of Soot Oxidation Rates," Combustion and Flame, Vol. 20, No. 3, 1973, pp. 369-379.

24. Neoh, K.G., Soot Burnout in Flames, Ph.D.

Thesis, Massachusetts Institute of Technology, Cambridge, MA, 1980.

25. Neoh, K.G., Howard, J.B., and Sarofim, A.F., "Soot Oxidation in Flames," Particulate Carbon (D.C. Siegla and B.W. Smith, ed), Plenum Press, New York, 1980,pp. 261-277.

26. Neoh, K.G., Howard, J.B., and Sarofim, A.F., "Effect of Oxidation on the Physical Structure of Soot," Proceedings of the Combustion Institute, Vol. 20, 1984,pp. 951-957.
27. Garo, A., Lahaye, J., and Prado, G., "Mechanisms of Formation and Destruction of Soot Particles in a Laminar Methane-Air Diffusion Flame," Proceedings of the Combustion Institute, Vol. 21, 1986, pp. 10231031.

28. Garo, A., Prado, G., and Lahaye, J., "Chemical Aspects of Soot Particles Oxidation in a Laminar Methane-Air Diffusion Flame," Combustion and Flame, Vol. 79, Nos. 3 and 4, 1990,pp. 226-233.

29. Hardiquert, M., Cessou, A., Stepowski, D., and Coppalle, A., "OH and Soot Concentration Measurements in a High-Temperature Laminar Diffusion Flame," Combustion and Flame, Vol. 111, No. 4, 1997,pp. 338-349.

30. Dalzell, W.H., and Sarofim, A.F., "Optical Constants of Soot and Their Application to Heat Flux Calculations," Journal of Heat Transfer, Vol. 91, No. 1, 1969, pp. 100-104.

31. Krishnan, S.S., Lin, K.-C., Wu, J.-S., and Faeth, G.M., "Optical Properties in the Visible of Overfire Soot in Large Buoyant Turbulent Diffusion Flames," Journal of Heat Transfer, Vol. 122, No. 3,2000, pp. 517-524.

32. Dobbins, R.A., and Megridis, C.M., "Morphology of Flame-Generated Soot as Determined by Thermophoretic Sampling," Langmuir, Vol. 3, No. 2, 1987, pp. 254-259.

33. Köylü, U.O., and Faeth, G.M., "Structure of Overfire Soot in Buoyant Turbulent Diffusion Flames at Long Residence Times," Combustion and Flame, Vol. 89, No. 2, 1992,pp. 140-156.

34. Tesner, P.A., "Formation of Dispersed Carbon by Thermal Decomposition of Hydrocarbons," Proceedings of the Combustion Institute, Vol. 7, 1958,pp. 546-556.

35. Tesner, P.A., "Dispersed Carbon Formation by Acetylene Self-Combustion," Proceedings of the Combustion Institute, Vol. 8, 1960, pp. 627-633.

36. Libby, P.A., and Blake, T.R., "Theoretical Study of Burning of Carbon Particles," Combustion and Flame, Vol. 36, No. 2, 1979, pp. 139-169. 
37. Libby, P.A., and Blake, T.R., "Burning of Carbon Particles in the Presence of Water Vapor," Combustion and Flame, Vol. 41, No. 2, 1981,pp. 123-147.

38. Johnstone, J.F., Chen, C.Y., and Scott, D.S., "Kinetics of the Steam-Carbon Reaction in Porous Graphite," Industrial Engineering Chemistry, Vol 44, 1952,pp. 1564-1569.

39. Bradley, D., Dixon-Lewis, G., El-Din Habik, S., and Mushi, E.M.J., "The Oxidation of Graphite Powder in Flame Reaction Zones," Proceedings of the Combustion Institute, Vol. 20, 1984,pp. 931-940.

40. Chase, M.W., Jr., Davies, C.A.,Downey, J.R., Jr., Frurip, D.J., McDonald, R.A., and Syverud, A.N., JANAF Thermochemical Tables, $3^{\text {rd }}$ Ed., J. Phys. Chem. Ref. Data, 14. (Suppl. 1), 1986, p. 1211.

Table 1. Test Laminar Jet Diffusion Flames ${ }^{\mathrm{a}}$

\begin{tabular}{lcccc}
\hline Test Flame & $\mathbf{1}$ & $\mathbf{2}$ & $\mathbf{3}$ & $\mathbf{4}$ \\
\hline Pressure (atrn) & $1 / 8$ & 114 & 112 & $\mathbf{1}$ \\
$\mathrm{C}_{2} \mathrm{H}_{2}$ in burner flow (\% by vol.) & 100 & 100 & 39.0 & 21.0 \\
$\mathrm{~N}_{2}$ in burner flow (\% by vol.) & 0.0 & 0.0 & 61.0 & 79.0 \\
Fuel flow rate (cc/s) & 30.9 & 10.2 & 4.9 & 2.7 \\
$\mathrm{~N}_{2}$ flow rate (cc/s) & 0.0 & 0.0 & 7.7 & 10.2 \\
Air coflow rate (cc/s) & 1190 & 392 & 132 & 34 \\
Burner exit velocity (mm/s) & 3610 & 1050 & 1470 & 1510 \\
Air coflow velocity (mm/s) & 16.8 & 5.5 & 1.9 & 0.5 \\
Luminous flame length (mm) & 50 & 50 & 50 & 50 \\
Stoich. flame length $(\mathrm{mm})$ & 25 & 35 & 33 & $\mathbf{4 1}$ \\
Re (-) & 170 & 98 & 197 & 376 \\
Fr (-) & 403 & 34 & 67 & 70 \\
Char. residence time (ms) & 5.1 & 10.0 & 10.9 & 13.1 \\
Stoich. flame temp. $(\mathrm{K})$ & 2430 & 2470 & 2400 & 2280 \\
\hline
\end{tabular}

${ }^{a}$ Round laminar jet diffusion flames with a $3.3 \mathrm{~mm}$ inside diameter burner with $\mathrm{C}_{2} \mathrm{H}_{2}-\mathrm{N}_{2}$ mixtures flowing from the burner in air coflow.

${ }^{\mathbf{b}}$ Nominal average value based on an injection temperature of $298 \pm 2 \mathrm{~K}$

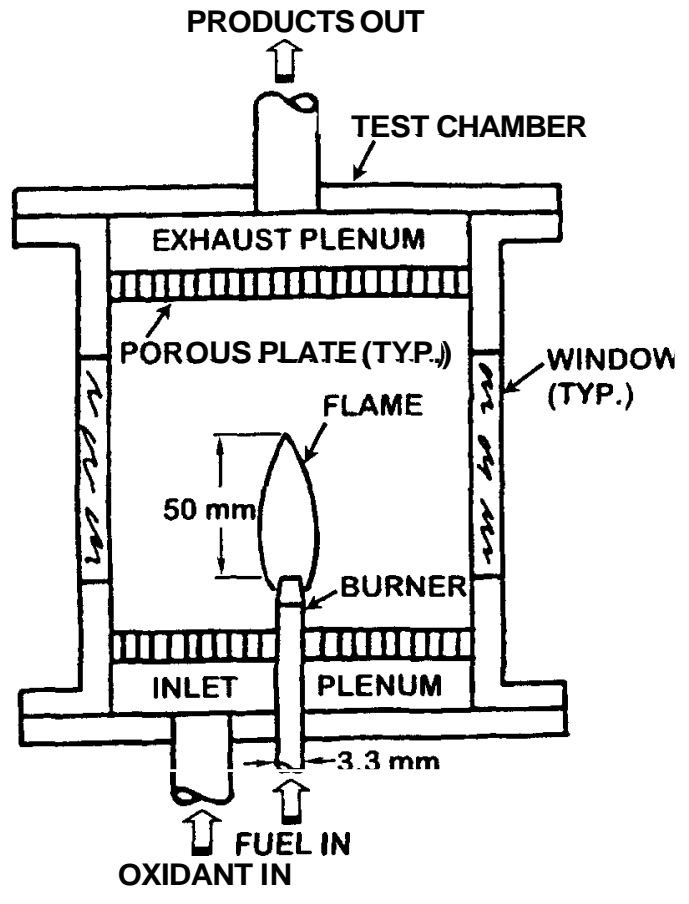

Fig. 1 Sketch of the laminar coflowing jet diffusion flame test apparatus

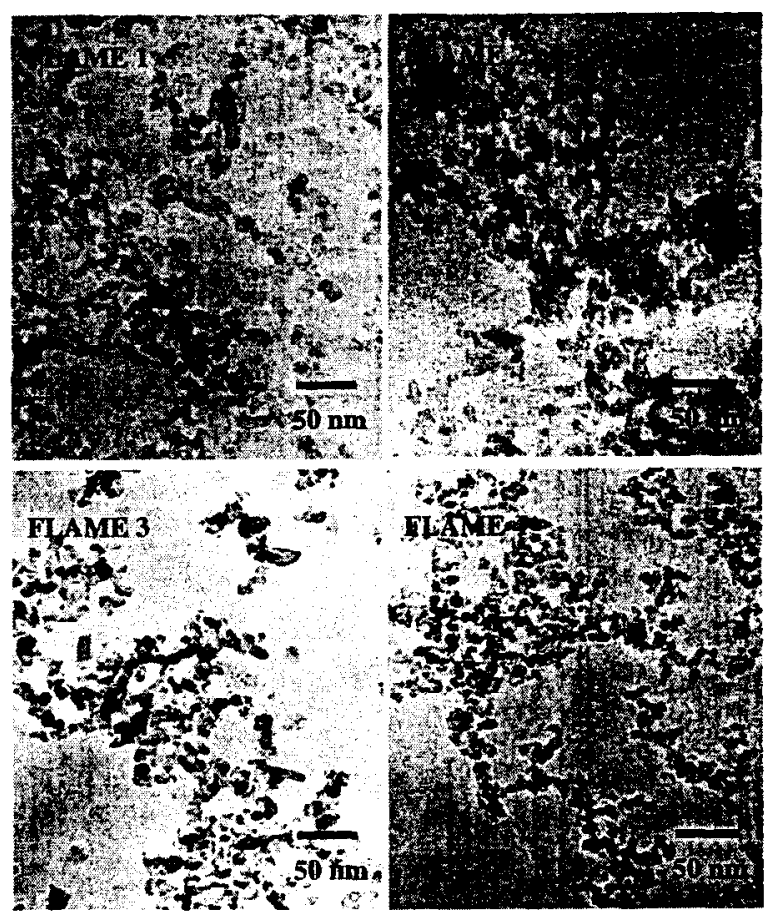

Fig. 2 TEM photographs of soot aggregates at the maximum soot volume fraction locations along the axes of acetylene-nitrogen-fueled flames burning in coflowing air at normal temperature: Flame 1 at 0.125 atm, Flame 2 at $0.250 \mathrm{~atm}$, Flame 3 at $0.500 \mathrm{~atm}$, and Flame 4 at 1.0atm.

13

American Institute of Aeronautics and Astronautics 


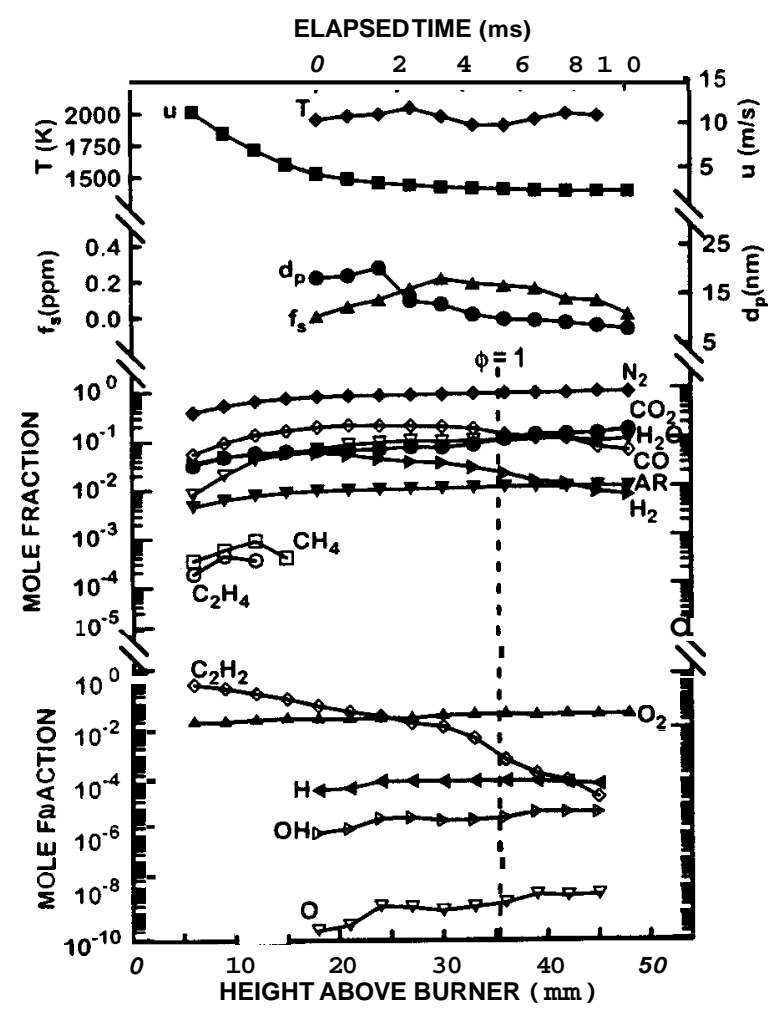

Fig. 3 Measured soot and flame properties along the axis of an acetylene/air laminar jet diffusion flame at $0.125 \mathrm{~atm}$ (Flame 1).

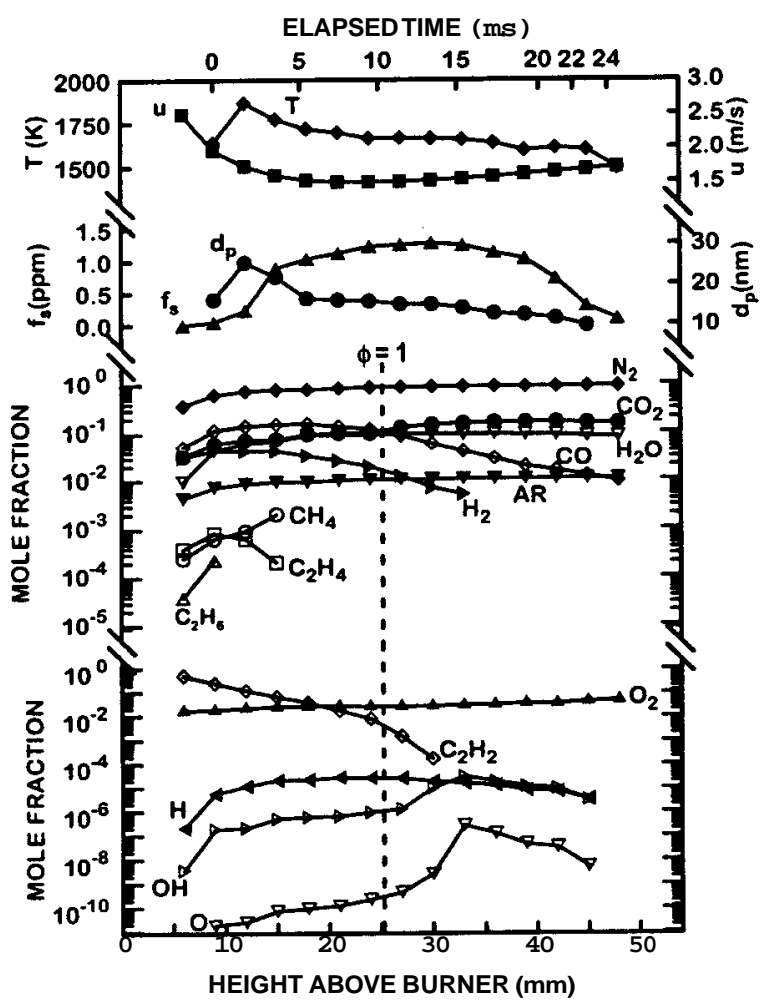

Fig. 4 Measured soot and flame properties along the axis of an acetylene/air laminar jet diffusion flame at $0.250 \mathrm{~atm}$ (Flame 2).

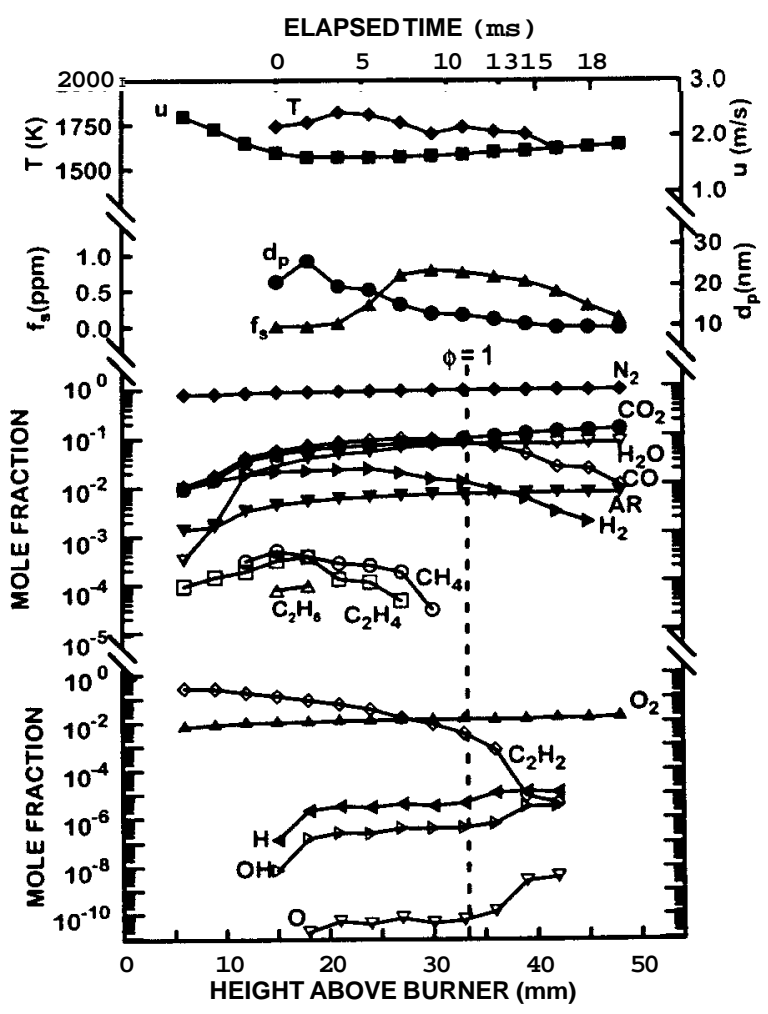

Fig. 5 Measured soot and flame properties along the axis of an acetylene-nitrogenlair laminar jet diffusion flame at $0.500 \mathrm{~atm}$ (Flame 3).

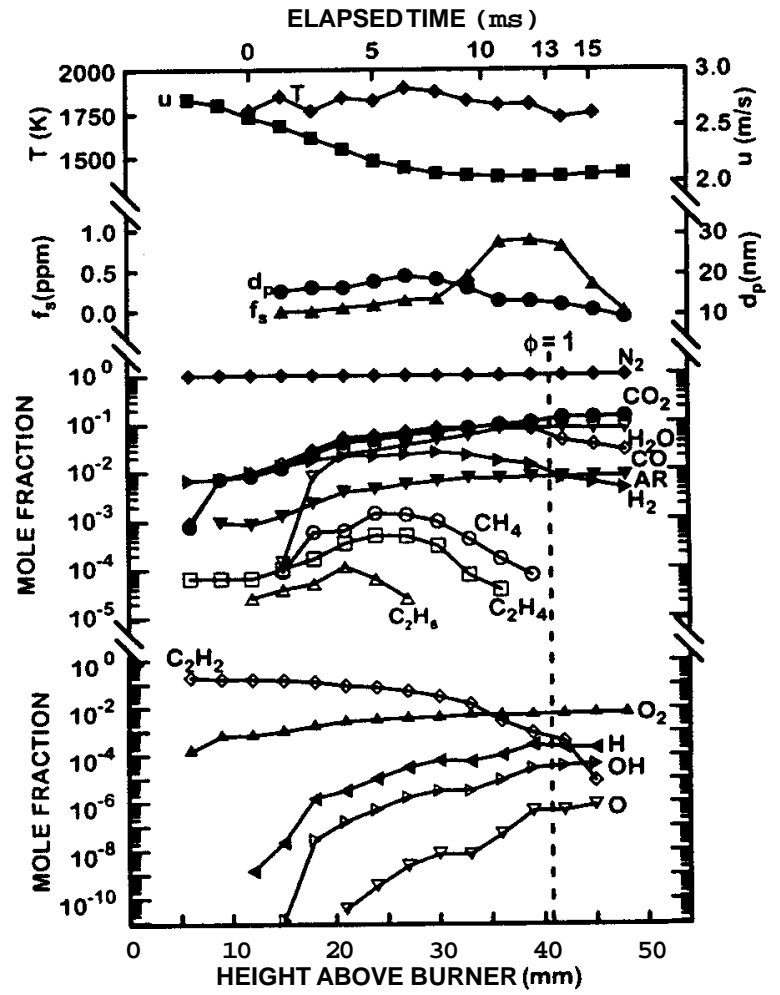

Fig. 6 Measured soot and flame properties along the axis of an acetylene-nitrogenlair laminar jet diffusion flame at $1.000 \mathrm{~atm}$ (Flame 4) . 


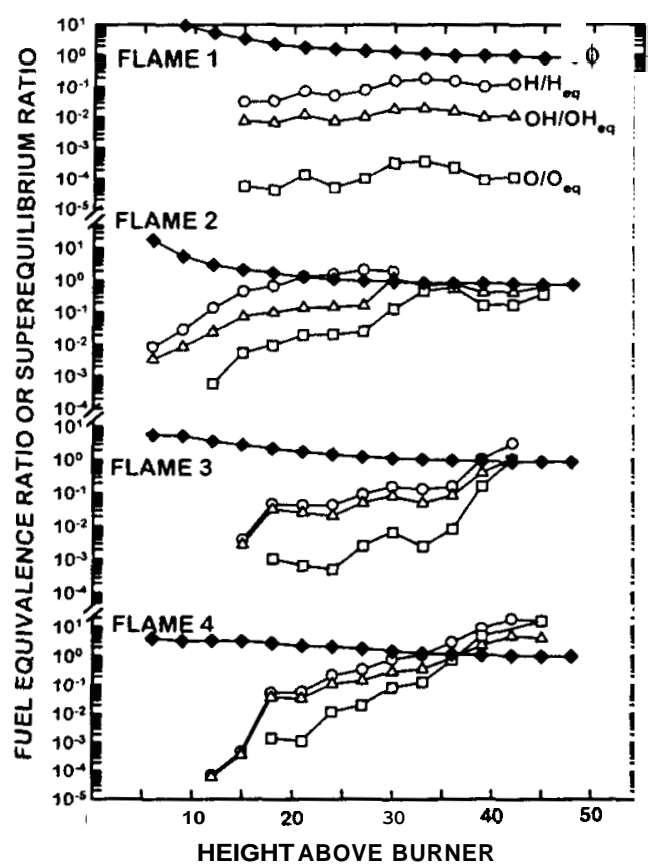

Fig. 7 Fuel equivalence and superequilibrium ratios along the axes of acetylene-nitrogen fueled flames burning in coflowing air at normal temperature: Flame 1 at 0.125 atm, Flame 2 at 0.250 atm, Flame 3 at $0.500 \mathrm{~atm}$, and Flame 4 at $1.0 \mathrm{~atm}$.

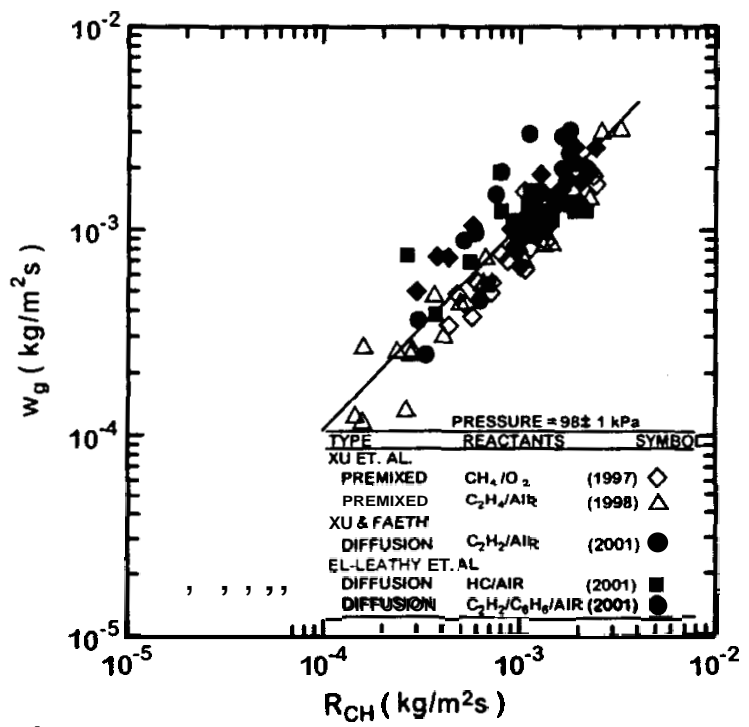

Fig. 8 Soot surface growth rates (corrected for soot surface oxidation) in terms of the HACA mechanism of Colket and Hall [18] for laminar flames at atmospheric pressure. Measurements of ethylene/air premixed flames from $\mathrm{Xu}$ et al. [4]; measurements of methane/oxygen premixed flames from Xu et al. [5]; measurements of acetylene-nitrogenlair diffusion flames from Xu and Faeth [7]; and measurements of ethylene/air, propylene-nitrogenlair, propane/air and acetylene-benzene-nitrogen/air diffusion flames from El-Leathy et al. [9].

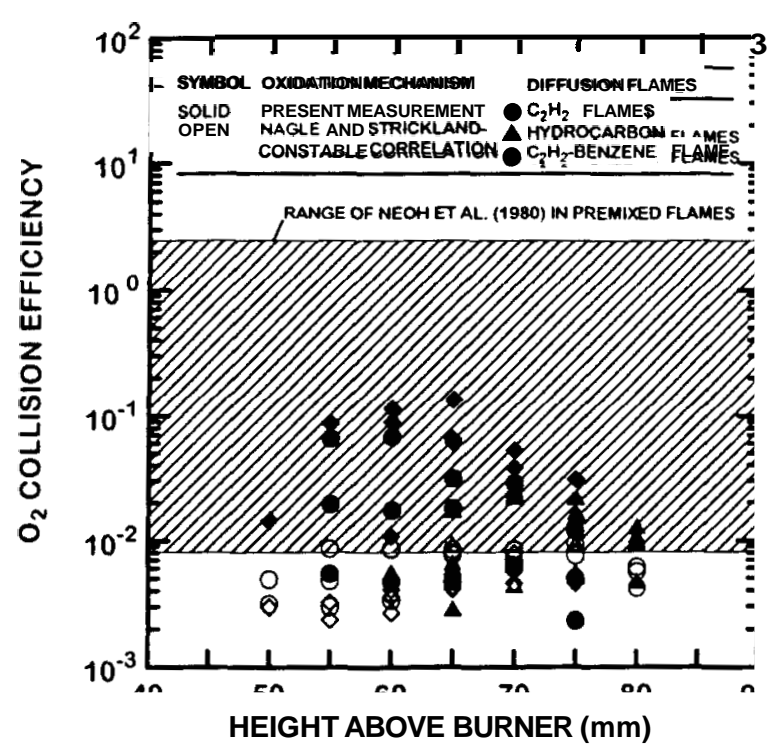

Fig. 9 Soot surface oxidation collision efficiencies assuming soot burnout due to attack by $\mathrm{O}_{2}$ as a function of height above the burner. Found from the measurements of Neoh et al. [24-26] in premixed flames estimated from the correlation for attack by $\mathrm{O}_{2}$ of Nagle and Strickland-Constable [22] and from the measurements of El-Leathy et al. [9] in diffusion flames.

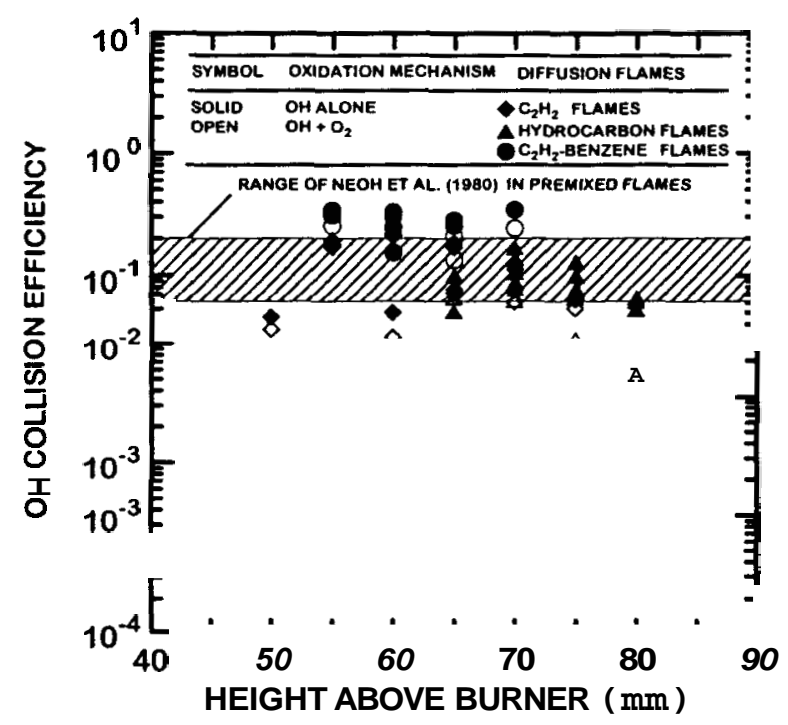

Fig. 10 Soot surface oxidation collision efficiencies assuming soot burning due to attack by $\mathrm{OH}$ as a function of height above the burner. Found from the measurements of Neoh et al. [24-26] in premixed flames and from the measurements of El-Leathy et al. [9] in diffusion flames.

15

American Institute of A.eronautics and Astronautics 
